\title{
Differentiation of Malignant from Benign Portal Vein Thrombi on CT Images Using Thrombus Density
}

\author{
MONA F.A. HANNOUT, M.Sc.; ADEL M. AL-WEKIL, M.D. and REHAB M. HABIB, M.D. \\ The Department of Radiology, Faculty of Medicine, Menofiya University, Menofiya, Egypt
}

\begin{abstract}
Background: Portal vein thrombosis described as the presence of a clot in the portal vein lumen or a permanent obliteration of the portal vein as a result of prior thrombosis with replacement by numerous tortuous venous channels (termed cavernoma). Malignant portal vein thrombus, so named for its neoplastic origin, is a common complication of $\mathrm{HCC}$, and, in some cases, it may be even the initial sign of an undetected HCC. Detection of malignant PVT in a patient with liver cirrhosis heavily affects the therapeutic strategy.
\end{abstract}

Aim of Study: The purpose of this study was to investigate the role of CT thrombus density (measured in Hounsfield Units) in distinguishing between neoplastic and bland portal vein thrombosis on arterial and portal venous phases.

Material and Methods: In this study, 30 patients underwent contrast-enhanced CT of abdomen \& pelvis were included for characterization of portal vein thrombosis. Assessment of portal vein thrombosis was performed by measuring of $\mathrm{CT}$ attenuation values of the thrombi in Hounsfield Units (HU).

ROC (Receiver Operating Characteristic) curves were used to identify accuracy and optimal cutoff values.

Results: Of the $30 \mathrm{CT}$ studies, 14 neoplastic thrombi and 13 bland thrombi were identified on the images. CT thrombus density (measured in Housinfield Unit) to differentiate neoplastic from bland thrombus. The AUCs was 0.98 in arterial phase and 0.98 in portovenous phase for thrombus density.

The optimal cut off in arterial phase is 47 and in portovenous phase is 50 .

Conclusion: CT attenuation values allow reliable differentiation between neoplastic and bland thrombi on arterial and portal venous phase CT examination.

Key Words: Triphasic CT $-P V T-C T$ density.

\section{Introduction}

LOCAL factors that precipitate thrombosis in the portal venous system in patients who are in a state of thrombophilia can be classified into three categories. The first category includes conditions that

Correspondence to: Dr. Mona F.A. Hannout, The Department of Radiology, Faculty of Medicine, Menofiya University, Menofiya, Egypt cause PVT due to local inflammation and infection [1] .

A second category of local factors includes blunt trauma and surgical procedures that cause injury to the portal venous system. Generally these do not precipitate PVT unless there is an associated prothrombotic state or portal hypertension. The last and most important group of conditions that cause PVT is neoplastic disease [2].

Neoplastic thrombus of the portal vein is found in $6.5 \%-44 \%$ of patients with Hepatocellular Carcinoma (HCC). Presence of neoplastic thrombus serves as an important determinant of tumor staging, as well as prognosis, and influences treatment selection. HCC invasion into the portal vein renders a patient unsuitable for aggressive treatment approaches such as surgical resection, orthotopic liver transplantation, or chemoembolization, due the unusually high incidence of tumor recurrence and dismal survival associated with this finding [3].

The findings of PVT of the dynamic CT are filling defect partially or totally occluding the vessel lumen and rim enhancement of the vessel wall, sometimes with extension into splenic or superior mesenteric veins. Unenhanced scans have been shown to be of minimal benefit in the identification of thrombus [4].

Indirect signs of PVT are the presence of portosystemic collateral vessels, cavernous transformation of the portal vein, and arterioportal shunts [5].

Malignant and benign thrombi can often be differentiated by radiologists on the basis of CT imaging characteristics [6]. 
CT radiological findings of tumor thrombus suggesting malignancy are: Dilatation of portal vein, intra thrombus neovascularity arterial enhancement in CT. Thread and streak sign multiple enhancing intraluminal smaller vessels that can be seen at arterial phase imaging. Contiguity to tumor often with direct invasion [7].

CT density: Mean thrombus density values can distinguish neoplastic and bland thrombi by measuring thrombus density (in Hounsfield Unit) in arterial and portal venous phase [8].

\section{Subjects and Methods}

This study was approved by Radiology Department at Menofiya University between period from December 2016 to December 2017.

In this study, we included all patients who underwent a contrast-enhanced CT examination of the abdomen and pelvis in the arterial and portal venous phases and for whom PVT was noted on the radiology reports. We excluded patients who did not undergo a contrast-enhanced portal venous phase CT examination, those without clinical or medical data for confirmation or follow-up examination regarding the nature of the thrombus.

\section{CT Technique:}

All the patients included in the study underwent contrast-enhanced (CECT) of the abdomen and pelvis. The studies were performed in the arterial and portal venous phase and were acquired at 20 $\& 80$ seconds after administration of IV contrast material. A total of $80-120 \mathrm{~mL}$ of nonionic iodinated contrast material $(300 \mathrm{mgI} / \mathrm{mL})$ was injected IV at $3 \mathrm{~mL} / \mathrm{s}$ for all patients. The scanning protocols and parameters included slice thickness of $5 \mathrm{~mm}$, weight-based tube potential $(100-120 \mathrm{kVp})$, automatic tube current modulation $(75-500 \mathrm{~mA})$, and 0.5 -second gantry rotation time. All the patients had multiplanar reformations in the coronal and sagittal plane with 3-mm thickness.

\section{Results}

This study was carried out on 30 patients presented to the Radiology Department at Menofiya University diagnosed to have portal vein thrombosis by triphasic CT.

All patients with malignant PVT showed enhancement of the thrombus in arterial phase, while all patients with benign PVT and cavernous transformation showed no enhancement (Table 1).
$15 \%$ of patients with benign PVT had collaterals, $28.5 \%$ of patients with malignant PVT had collaterals and $100 \%$ of patients with chronic thrombus with cavernous transformation were found to have collaterals (Table 1).

There is $50 \%$ of patients with malignant PVT were found to have an AP shunt. Non of patients with benign thrombi had an AP shunt (Table 1).

Table (1): Comparison between benign, malignant PVT \& cavernous transformation.

\begin{tabular}{|c|c|c|c|c|c|c|c|}
\hline & \multicolumn{2}{|c|}{$\begin{array}{l}\text { Benign } \\
\text { (13) }\end{array}$} & \multicolumn{2}{|c|}{$\begin{array}{l}\text { Malignant } \\
\text { (14) }\end{array}$} & \multicolumn{2}{|c|}{$\begin{array}{c}\text { Cavernous } \\
\text { transformation } \\
(3)\end{array}$} & \multirow{2}{*}{$\begin{array}{c}p- \\
\text { value }\end{array}$} \\
\hline & No. & $\%$ & No. & $\%$ & No. & $\%$ & \\
\hline \multicolumn{8}{|l|}{ Cirrhosis: } \\
\hline Yes & 11 & 84 & 14 & 100 & 3 & 100 & 0.41 \\
\hline No & 3 & 16 & 0 & 0.0 & 0 & 0.0 & \\
\hline \multicolumn{8}{|l|}{$H C C$ : } \\
\hline Yes & 6 & 46.0 & 14 & 100 & 1 & 33 & 0.04 \\
\hline No & 7 & 54.0 & 0 & 0.0 & 2 & 67 & \\
\hline \multicolumn{8}{|l|}{ Embolization: } \\
\hline Yes & 4 & 30 & 2 & 14 & 0 & 0 & 0.54 \\
\hline No & 9 & 70 & 12 & 86 & 3 & 100.0 & \\
\hline \multicolumn{8}{|l|}{ Ablation: } \\
\hline Yes & 2 & 15 & 1 & 7 & 1 & 33 & 0.46 \\
\hline No & 11 & 85 & 13 & 93 & 2 & 67 & \\
\hline \multicolumn{8}{|l|}{ High AFP: } \\
\hline Yes & 6 & 46 & 14 & 100 & 0 & 0 & 0.015 \\
\hline No & 7 & 54 & 0 & 0.0 & 3 & 100 & \\
\hline \multirow[t]{2}{*}{ Dilated caliber } & 5 & 38 & 6 & 42 & 0 & 0 & 0.94 \\
\hline & 8 & 62 & 8 & 58 & 3 & 100 & \\
\hline Enhancement & 0 & 0 & 14 & 100 & 0 & 0 & \\
\hline \multicolumn{8}{|l|}{ Collaterals: } \\
\hline Yes & 2 & 15 & 4 & 28 & 3 & 100 & 0.65 \\
\hline No & 11 & 85 & 10 & 72 & 0 & 0.0 & \\
\hline \multicolumn{8}{|l|}{ AP shunt: } \\
\hline Yes & 0 & 0 & 7 & 50 & 0 & 0 & 0.04 \\
\hline No & 13 & 100 & 7 & 50 & 3 & 100 & \\
\hline \multicolumn{8}{|l|}{ Ascitis: } \\
\hline Yes & 2 & 15 & 6 & 42 & 1 & 33 & 0.29 \\
\hline No & 11 & 85 & 8 & 58 & 2 & 67 & \\
\hline Tumor invasion & 0 & 0 & 14 & 100 & 0 & 0 & \\
\hline
\end{tabular}

Out of 30 patients, 27 (13 cases) with benign portal vein thrombus, (14 cases) with malignant thrombus and the following study is detected:

Sensitivity of thrombus density in the precontrast phase is $53 \%$, specificity $50 \%$ and accuracy $50 \%$, sensitivity of thrombus density in arterial phase is $100 \%$, specificity $93 \%$ and accuracy $100 \%$, sensitivity of thrombus density in the porto-venous phase is $100 \%$, specificity $93 \%$ and accuracy $100 \%$. The best cut off in pre-contrast phase is 25.5 , in arterial phase is 47 and in porto-venous phase is 50 (Table 2). 
Table (2): Sensitivity and specificity of HU in detection nature of thrombus.

\begin{tabular}{lccccccc}
\hline & AUC & $\begin{array}{r}\text { Best cut } \\
\text { off (HU) }\end{array}$ & Sensitivity & Specificity & PPV & \multicolumn{2}{c}{ NPV Accuracy } \\
\hline Density thrombus pre-contrast & 0.552 & 25.5 & $53 \%$ & $50 \%$ & $65 \%$ & $54 \%$ & $50 \%$ \\
Density thrombus arterial & 0.981 & 47 & $100 \%$ & $93 \%$ & $100 \%$ & $100 \%$ & $100 \%$ \\
Density thrombus porto-venous & 0.981 & 50 & $100 \%$ & $93 \%$ & $100 \%$ & $100 \%$ & $100 \%$ \\
\hline
\end{tabular}

*: AUC (Area Under Curve) is significant if more than 0.7 .
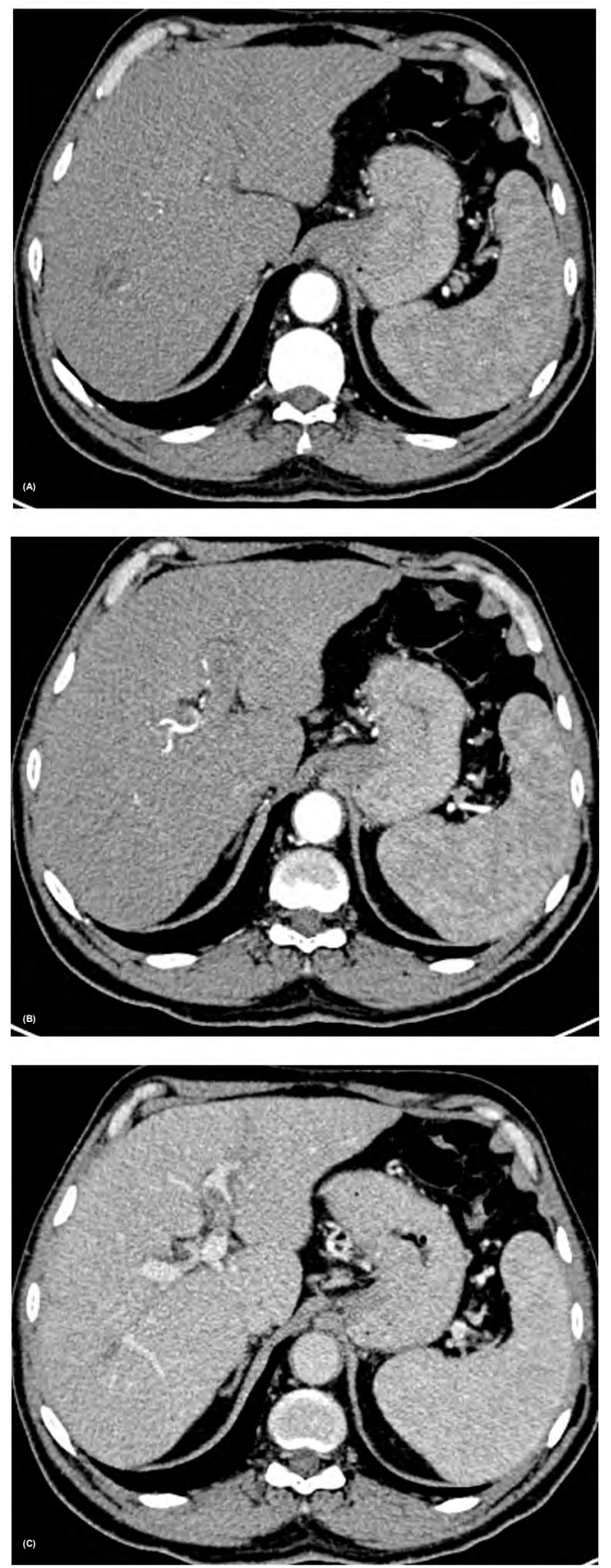

Fig. (1): Male patient 64 years old presented with disturbed liver functions, hypodense lesion in segement VII in precontrast phase shows no arterial enhancement or washout in delayed phases. Adequately ablated HCC Fig. (1A). Hypodense non enhanced thrombus $(30 \mathrm{HU})$ in left main portal vein in arterial (33HU) Fig. (1B) and portovenous phases (39HU) Fig. (1C).
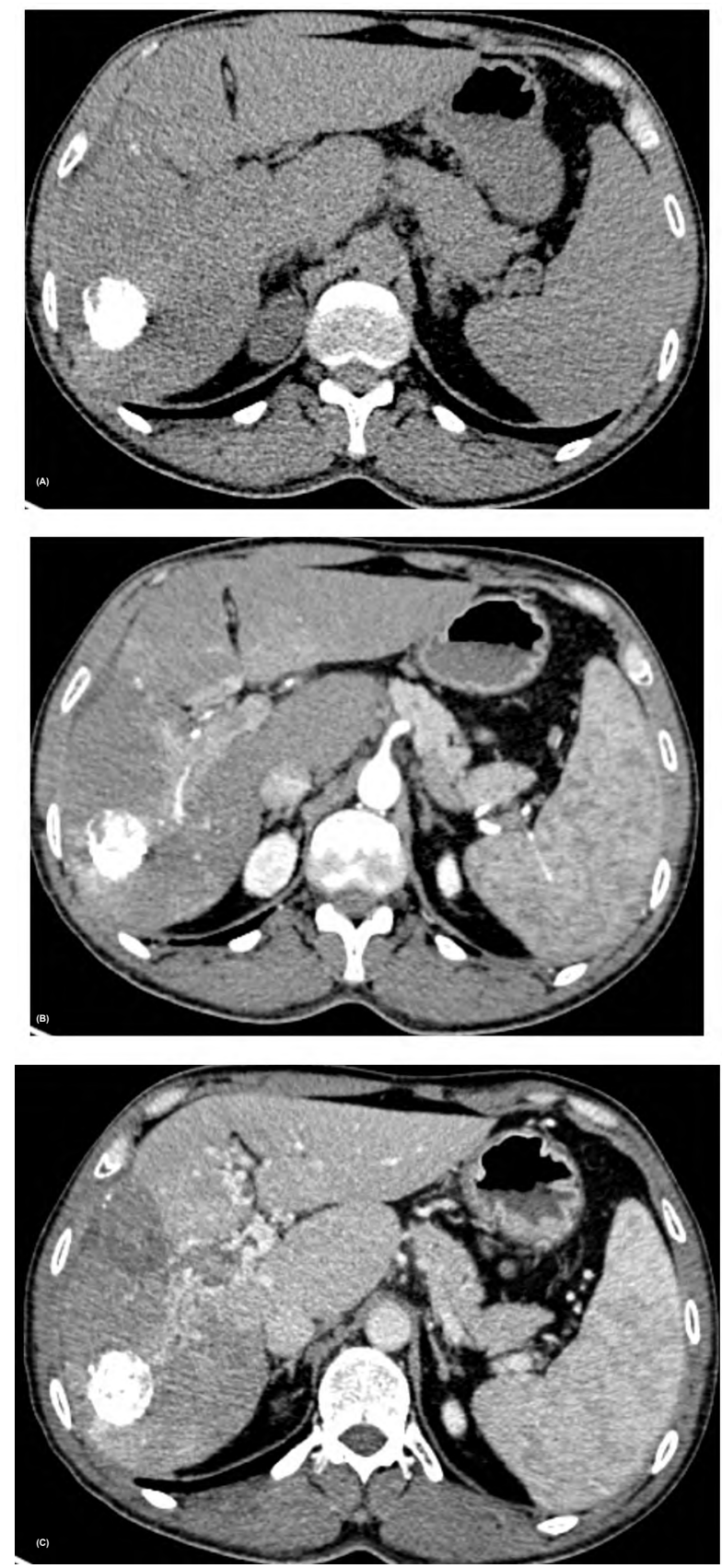

Fig. (2): Male patient 65 years old had history of HCC and he underwent symptoms, right lobe arterially enhancing hepatic focal lesion inadequately managed by TACE (transarterial chemoembolization) with lipidol uptake Fig. (2A). Right main portal vein is distended by a thrombus which is isodense in precontrast phase $(33 \mathrm{HU})$ and shows arterial enhancement (74HU) Fig. (2B) and washout in portovenous phase (84) Fig. (2C). 


\section{Discussion}

Dynamic contrast enhanced CT is the best means of diagnosis of PVT and evaluation of various causative diseases [9].

In the current study, all patients with malignant PVT (100\%) showed enhancement of the thrombus in arterial phase and washout in portovenous phase while all patients with benign PVT and cavernous transformation showed no enhancement, our results in agreement with the study of Osman [10] they found that on tri-phasic CT of the 33 patients with malignant PVT, 28 (84.8\%) patients showed neovascularity of PVT, early arterial enhancement and rapid washout of the thrombus (29/33) (87.8\%) and none of the 17 patients with benign PVT showed intrathrombus neovascularity or enhancement.

In our study, sensitivity of thrombus density in pre-contrast phase $53 \%$, specificity $50 \%$ and accuracy $50 \%$, sensitivity of thrombus density in arterial phase $100 \%$, specificity $93 \%$ and accuracy $100 \%$, sensitivity of thrombus density in porto-venous phase $100 \%$, specificity $93 \%$ and accuracy $100 \%$. The best cut off value to diagnose malignant thrombus in arterial phase is $47 \mathrm{HU}$ and in porto-venous phase is $50 \mathrm{HU}$. AUC is more than 0.7 in arterial and poto-venous phases (significant) but in precontrast phase is less than 0.7 so this phase is nonsignificant in differentiating between benign and malignant and this match with the study of Canellas [11] mean thrombus density values could also reliably distinguish neoplastic ( $81.39 \mathrm{HU})$ and bland (32.88HU) thrombi. The optimal cutoffs values were $54 \mathrm{HU}$ for thrombus density in porto venous phase. This match with our study to diagnose malignant thrombus as optimal cut offs value by $\mathrm{HU}$ in porto-venous phase similar.

\section{Conclusion:}

CT attenuation values allow reliable differentiation between neoplastic and bland thrombi on arterial and portal venous phase CT examination.

\section{References}

1- TARANTINO L., AMBROSINO P., MINNO M., et al. Contrast-enhanced ultrasound in differentiating malignant from benign portal vein thrombosis in hepatocellular carcinoma. World J. Gastroenterol., 21 (32): 9457-60, 2015.

2- EGESEL T., BUYUKASIK Y., DUNDAR S.V., et al.: The role of natural anticoagulant deficiencies and factor $\mathrm{V}$ Leiden in the development of idiopathic portal vein thrombosis. J. Clin. Gastroenterol., 30: 66-71, 2000.

3- SUN L., GUAN Y.S., PAN W.M., et al.: Positron emission tomography computer tomography in guidance of extrahepatic hepatocellular carcinoma metastasis management. World J. Gastroenterol., 13: 5413-5, 2007.

4- PISCAGLIA F., GIANSTEFANI A., RAVAIOLI M., et al.: Criteria for Diagnosing Benign Portal Vein Thrombosis in the Assessment of Patients with Cirrhosis and Hepatocellular Carcinoma for Liver Transplantation. Liver transplantation, 16: 658-67, 2010.

5- PONZIANI F.R., ZOCCO M.A., CAMPANALE C., et al.: Portal vein thrombosis: Insight into physiopathology, diagnosis, and treatment. World J. Gastroenterol., 16: 143-55, 2010.

6- BERZIGOTTI A., CRIADO A.G., DARNELL A., et al.: Imaging in clinical decision-making for portal vein thrombosis nature reviews Gastroenterology \& Hepatology, 11: 308-16, 2014

7- NG F., KOZARSKI R., GANESHAN B., et al.: Assessment of tumor heterogeneity by CT texture analysis: Can the largest cross sectional area be used as an alternative to whole tumor analysis? Eur. J. Radiol., 82: 342-8, 2013.

8- RYU Y.J., CHOI S.H., PARK S.J., et al.: Application of whole-tumor texture analysis of diffusion-weighted imaging for the evaluation of tumor heterogeneity. PLoS One, 9: 787-96, 2014.

9- LEE W.K., CHANG S.D., DUDDALWAR V.A., et al.: Imaging assessment of congenital and acquired abnormalities of the portal venous system. Radiographics, 31 (4): 905-26, 2011

10- OSMAN N., SAMY L., et al.: Benign and malignant portal venous thrombosis: Multi-modality imaging evaluation. The Egyptian Journal of Radiology and Nuclear Medicine, 47: 387-97, 2016.

11- CANELLAS R., MEHRKHANI F., PATINO M., et al.: Characterization of Portal Vein Thrombosis (Neoplastic Versus Bland) on CT Images Using Software-Based Texture Analysis and Thrombus Density (Hounsfield Units). A.J.R., 207: 81-7, 2016. 


\section{التفريق بين خثرة الوريل البا بى الحميلدة والخبيثة عن طريق الآشعة المقطعية بإستخدام كثافة الخثرة البيدة}

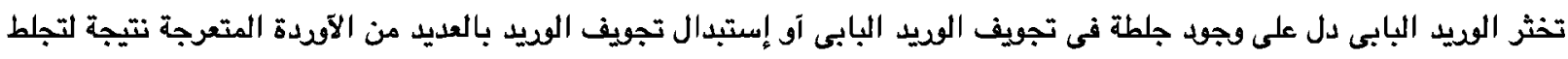

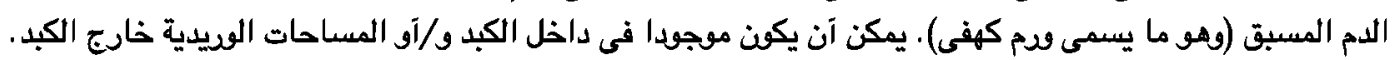

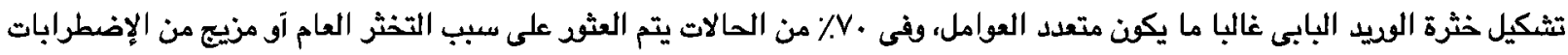

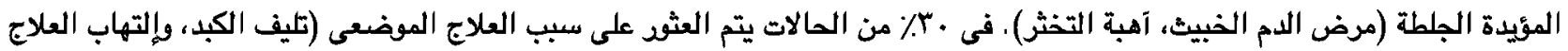

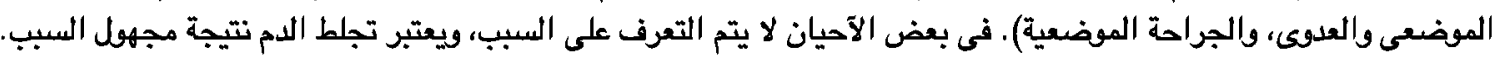

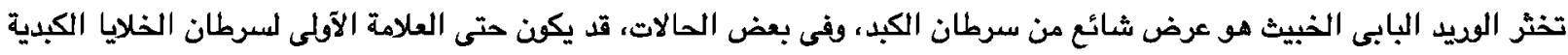

التى لم يتم كثفها . الكثف عن تفثر الوريد البابى الفييث فى مرضى يعانون من تليف الكبد يؤثر بثكل كيير على إستراتيجية العلاج.

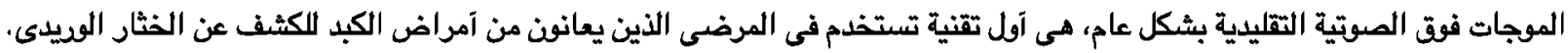

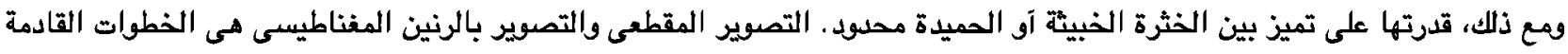

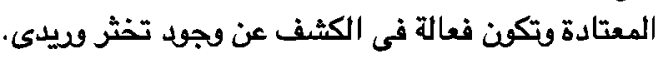

تبقى الآشعة المقطعية الوسيلة الرئيسية لتوصيف تخثر الويد البابى، ويرسخ المعايير الواضحة للتمييز بين الجلطة الدموية الضيية والحميدة

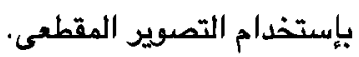

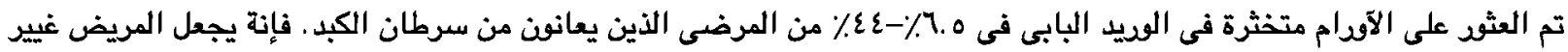

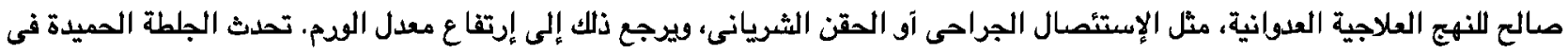

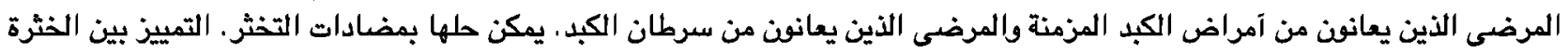

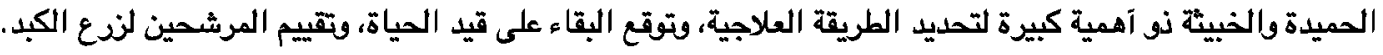

